\title{
NOTE
}

\section{VAPOR PRESSURE AND THIRD-LAW ENTROPY OF FERROCENE}

JOHN T. S. ANDREWS AND EDGAR F. WESTRUM, JR.

Department of Chemistry, University of Michigan, Ann Arbor, Michigan 48104 (U.S.A.)

(Received January 31st; 1969)

Subsequent to Edwards and Kington's ${ }^{1}$ use of a third-law entropy theck to show that the rings in the ferrocene (dicyclopentadienyliron) molecule rotate essentially freely about the ring-to-metal bond, new data relevant to the statistical calculation of the entropy have appeared and imply the desirability of performing the entropy check anew. The frequency assignments of Lippincott and Nelson ${ }^{2}$ used in evaluating the vibrational entropy of the molecule have been superceded by the assignment of Stammreich (reported by $\mathrm{Fritz}^{3}$ ), and the structural parameters affecting rotational entropies are now available from the electron-diffraction study of Bohn and Haaland ${ }^{4}$

TABLE 1

FREQUENCY ASSIGNMENTS FOR FERROCENE ${ }^{a}$

\begin{tabular}{|c|c|c|c|c|c|c|c|}
\hline \multirow{2}{*}{$\begin{array}{l}\text { Symmetry } \\
\text { species }^{b}\end{array}$} & \multirow{2}{*}{$\begin{array}{l}\text { Frequency } \\
\text { number }\end{array}$} & \multicolumn{2}{|c|}{ Frequencies } & \multirow{2}{*}{$\begin{array}{l}\text { Symmetry } \\
\text { species }^{b}\end{array}$} & \multirow{2}{*}{$\begin{array}{l}\text { Frequency } \\
\text { number }\end{array}$} & \multicolumn{2}{|c|}{ Frequencies } \\
\hline & & Ref. 3 & Ref. 2 & & & Ref. 3 & Ref. 2 \\
\hline \multirow{3}{*}{$A_{1 g}$} & 1 & 3110 & 3099 & \multirow{3}{*}{$A_{2 u}$} & 8 & 3086 & 3085 \\
\hline & 3 & 1390 & 1105 & & 10 & 1408 & 1108 \\
\hline & 4 & 306 & 303 & & 11 & 478 & 478 \\
\hline$A_{2 \mathrm{u}}$ & 9 & 1104 & 811 & $A_{1 g}$ & 2 & 1105 & 804 \\
\hline \multirow[t]{2}{*}{$A_{2 g}$} & \multirow[t]{2}{*}{7} & \multirow[t]{2}{*}{$(1249)$} & \multirow[t]{2}{*}{1200} & \multirow[t]{2}{*}{$A_{1 u}$} & 5 & (1253) & 1200 \\
\hline & & & & & 6 & \multicolumn{2}{|c|}{ Torsion } \\
\hline \multirow[t]{3}{*}{$E_{1 g}$} & 14 & 818 & 800 & \multirow[t]{3}{*}{$E_{14}$} & 19 & 814 & 834 \\
\hline & 16 & 390 & 388 & & 21 & 490 & 492 \\
\hline & & & & & 22 & $(170)$ & 150 \\
\hline \multirow[t]{3}{*}{$E_{14}$} & 17 & 3086 & 3075 & \multirow[t]{3}{*}{$E_{19}$} & 12 & 3089 & 3085 \\
\hline & 18 & 1004 & 1002 & & 13 & 998 & 1010 \\
\hline & 20 & 1408 & 1411 & & 15 & 1412 & 1408 \\
\hline \multirow[t]{4}{*}{$E_{2 g}$} & 23 & 3045 & 3085 & \multirow[t]{4}{*}{$E_{2 x t}$} & 29 & (3035) & 3100 \\
\hline & 24 & 1361 & 1178 & & 30 & (1351) & 1170 \\
\hline & 26 & 1527 & 1590 & & 32 & [1527] & 1550 \\
\hline & 27 & 1054 & 900 & & 33 & (1054) & 900 \\
\hline \multirow[t]{2}{*}{$E_{2 u}$} & 31 & (1188) & 1050 & \multirow[t]{2}{*}{$E_{\mathbf{2}_{g}}$} & 25 & 1184 & 1050 \\
\hline & 34 & $(567)$ & 500 & & 28 & 591 & 500 \\
\hline
\end{tabular}

- Units: $\mathrm{cm}^{-1}{ }^{b}$ The frequencies of the $E$ species are doubly degenerate. 
rather than from the X-ray study of Eiland and Pepinsky ${ }^{5}$ (used by Edwards and Kington). The electron diffraction determination also provides an independent estimate of the energy barrier to internal rotation.

Both sets of vibrational frequency assignments for ferrocene are listed in Table 1 ; those of Stammreich are employed for the computation of the entropy contributions $\left(S_{\text {trans }}+S_{\mathrm{rot}}+S_{\mathrm{vib}}+S_{\mathrm{ir}}=S_{\mathrm{tol}}\right)$ listed for several temperatures in Table 2. Comparison

TABLE 2

STANDARD SPECTROSCOPIC ENTROPY OF FERROCENE

\begin{tabular}{|c|c|c|c|c|c|c|}
\hline$T$ & $S_{\text {srans }}^{o}$ & $S_{\text {ror }}$ & $S_{\text {vib }}$ & $S_{i r}$ & $\begin{array}{l}S^{\infty}(g)^{b} \\
\text { (spectro) }\end{array}$ & $\Delta S_{r r}{ }^{r}$ \\
\hline 270 & 41.08 & 24.38 & 12.04 & 5.37 & 82.87 & -0.31 \\
\hline 273.15 & 41.13 & 24.41 & 12.29 & 5.38 & 83.21 & -0.30 \\
\hline 280 & 41.26 & 24.49 & 12.84 & 5.40 & 83.99 & -0.29 \\
\hline 290 & 41.43 & 24.59 & 13.66 & 5.44 & 85.12 & -0.27 \\
\hline 298.15 & 41.57 & 24.67 & 14.34 & 5.46 & 86.04 & -0.26 \\
\hline \multirow[t]{2}{*}{300} & 41.60 & 24.69 & 14.50 & 5.47 & 86.26 & -0.25 \\
\hline & & & & & \pm 0.3 & $\pm 0.15^{d}$ \\
\hline
\end{tabular}

${ }^{a}$ Units: cal, mole, ${ }^{a} \mathrm{~K} .{ }^{b}$ For the freely rotating system. ${ }^{c} \Delta S_{\mathrm{rr}}$ is the entropy decrement from the free to the restricted rotator. "At $298.15^{\circ} \mathrm{K}$, based on Haaland's uncertainty in the barricr height.

of the spectroscopic $S_{\text {zot }}$ with $S^{\circ}$ gas as evaluated using the vapor pressure data of Edwards and Kington leads to an entropy discrepancy of about $1.6 \mathrm{cal} \cdot \mathrm{mole}^{-1 .{ }^{0}} \mathrm{~K}^{-1}$ in the sense opposite to that explicable by the use of the Third Law. The concern is accented by Turnbull's ${ }^{6}$ use of these new data together with empirical relationships regarding the entropy of sublimation of dicyclopentadienyl metal compounds to obtain an "entropy discrepancy" of $1.2 \mathrm{cal} \cdot \mathrm{mole}^{-1} \cdot{ }^{\circ} \mathrm{K}^{-1}$ which he attributed to vibrational anharmonicity, etc.

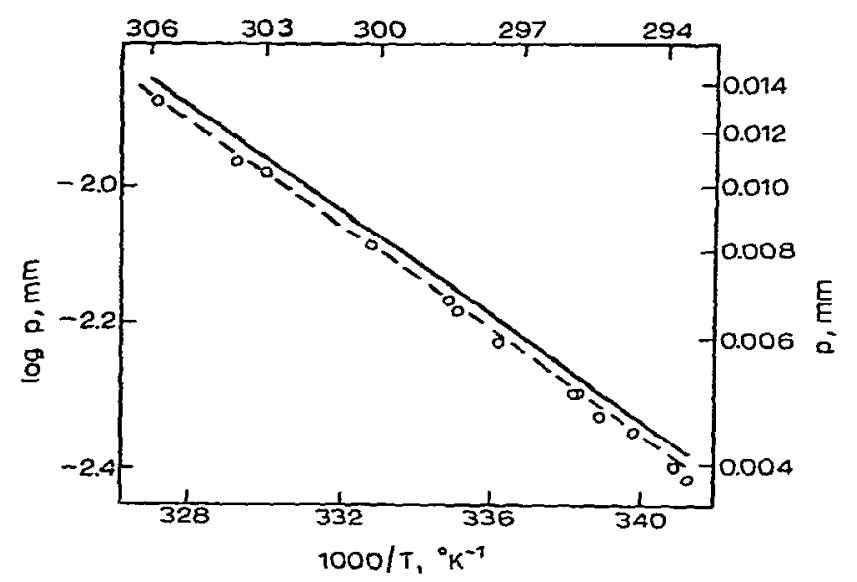

Fig. 1. The vapor pressure of ferrocene as a function of temperature. The $O$ represent the experimental determinations of this research. The dashed line represents the least squares fit to these values, and the solid line is the curve reported by Edwards and Kington ${ }^{2}$. 
We, therefore, redetermined the vapor (or sublimation) pressure of ferrocene using a Knudsen effusion apparatus similar to that described by Edwards and Kington. The resultant pressures computed according to the formulations described elsewhere ${ }^{7}$, are compared in Fig. 1 with those previously reported ${ }^{1}$ and may be represented by the relationship ( $p$ in $\mathrm{mm}, T$ in ${ }^{\circ} \mathrm{K}$ ) :

$$
\log _{10} p=A+B / T+C \cdot \log _{10} T
$$

in which $A=28.17 \pm 0.10, B=-4581 \pm 29^{\circ} \mathrm{K}$ and $C=-6.04$. The values of $A$ and $B$ were determined by a least squares analysis of the data; that of $C$ was constrained to accord with the difference between the measured heat capacity of the crystal phase and the calculated heat capacity of the vapor phase. The enthalpy and entropy of vaporization may then be expressed as:

$$
\begin{aligned}
& \Delta H_{\text {vap }}=20.96 \pm 0.13-0.012 T\left(\mathrm{kcal} \cdot \mathrm{mole}^{-1}\right) \\
& \Delta S_{\text {vap }}=(20960 \pm 130) / T-12\left(\mathrm{cal} \cdot \mathrm{mole}^{-1 .}{ }^{\circ} \mathrm{K}^{-1}\right)
\end{aligned}
$$

Haaland and Nilsson ${ }^{8}$ evaluated the energy barrier to internal rotation in ferrocene as $900 \pm 300 \mathrm{cal} \cdot \mathrm{mole}^{-1}$. This value with the partition function for the free rotor enables us to calculate the entropy decrement between the free and the restricted rotor ( $c f$. Pitzer and Brewer ${ }^{9}$ ). The calculation shows the entropy of the restricted rotor to be about $0.3 \mathrm{cal} \cdot \mathrm{mole}^{-1 .}{ }^{\circ} \mathrm{K}^{-1}$ lower than that of the free rotor. As shown in Table 3, the total statistico-mechanical entropy based on the new spectral and

TABLE 3

ENTROPY COMPARISON FOR FERROCENE ${ }^{a}$

\begin{tabular}{lllllll}
\hline$T$ & $S^{\circ}(\mathrm{c})^{h}$ & $\Delta S_{\text {vap }}{ }^{c}$ & $\Delta S_{\text {comp }}{ }^{d}$ & $\begin{array}{l}S^{\circ}(\mathrm{g}) \\
\text { (3rd Law) }\end{array}$ & $\begin{array}{l}S^{\circ}(\mathrm{g}) \\
\text { (spectro) }\end{array}$ & $S^{\circ}-S^{\circ}$ \\
\hline 270 & 47.29 & 65.64 & -29.35 & 83.58 & 82.87 & 0.71 \\
273.15 & 47.78 & 64.74 & -28.59 & 83.93 & 83.21 & 0.72 \\
280 & 48.84 & 62.87 & -27.01 & 84.70 & 83.99 & 0.71 \\
290 & 50.40 & 60.29 & -24.85 & 85.84 & 85.12 & 0.72 \\
298.15 & 51.68 & 58.31 & -23.21 & 86.78 & 86.04 & 0.74 \\
300 & 51.97 & 57.88 & -22.85 & 87.00 & 86.26 & 0.74 \\
& & & \pm 0.3 & \pm 0.5 & \pm 0.3 & \pm 0.6
\end{tabular}

${ }^{a}$ Units : cal, mole. ${ }^{\circ} \mathrm{K}$. ' Standard entropy of crystal, from ref. 1. ${ }^{\circ} \Delta S_{\text {vap }}$ entropy of vaporization (sublimation) at $T \cdot{ }^{d} \Delta S_{\text {comp }}$ entropy of compression from saturation pressure to one atm.

structural data accords (within experimental error, $0.7 \pm 0.6 \mathrm{cal} \cdot \mathrm{mole}{ }^{-1} \cdot{ }^{\circ} \mathrm{K}^{-1}$ ) with the third-law entropy calculated in part from the sublimation pressure data reported herein. Inclusion of the term from Table 2 calculated for the rotational barrier of Haaland worsens the agreement by $0.3 \pm 0.2 \mathrm{cal} \cdot \mathrm{mole}^{-1} \cdot{ }^{\circ} \mathrm{K}^{-1}$. The presence of a small barrier to the rotation of the cyclopentadienyl rings about the main symmetry axis cannot certainly be excluded if allowance is made for neglect of vibrational anharmonicity and possible rotation-vibration coupling.

Standard deviations have been used for precision indices throughout. 


\section{ACKNOWLEDGEMENT}

The generous support of this research by the U.S. Atomic Energy Commission is acknowledged with gratitude.

\section{REFERENCES}

I J. W. Edwards and G. L. KIngton, Trans. Faraday Soc., 58 (1962) 1334.

2 E. R. LipPINCOTt AND R. D. Nelson, Spectrochim. Acta, 10 (1958) 307.

3 H. P. Fritz, Advan. Organometal. Chem., 1 (1964) 239.

4 R. K. Buhn And A. HaAland, J. Organomelal. Chem., 5 (1966) 470.

5 P. F. Eilland and R. Pepinsky, J. Amer. Chem. Soc., 74 (1952) 4971.

6 A. G. Turndull, Aust. J. Chem., 20 (1967) 2757.

7 J. T. S. ANDrews and E. F. Westrum, JR., J. Organometal. Chem., 17 (1969) 293.

8 A. Haaland and J.-E. Nilsson, Chem. Commun., (1968) 88.

9 K. S. Pitzer and L. Breiver, in G. N. Lewis and Merle Randall (Eds.), Thermodynamics, McGrawHill, New York, 1961, p. 446.

J. Organometal. Chem., 17 (1969) 349-352 